\title{
Left Ventricles of the Mature Camel Heart (Camelus dromedaries) with Special References to the Structure and Distribution of the Purkinje Cardiomyocytes: Microanatomy
}

\author{
Ghonimi W*, Abuel-Atta AA, Bareedy MH and Balah A \\ Department of Histology and Cytology, Faculty of Veterinary Medicine, Zagazig University, 44519 Zagazig, Egypt \\ "Corresponding author: Waelghonimi, Department of Histology and Cytology, Faculty of Veterinary Medicine, Zagazig University, 44519 Zagazig, Egypt, Tel: \\ 00201222498246; E-mail: waghonimi@zu.edu.eg; drwael_histology@yahoo.com
}

Rec date: April 05, 2014; Acc date: April 23, 2014; Pub date: May 02, 2014

Copyright: () 2014 Ghonimi, et al. This is an open-access article distributed under the terms of the Creative Commons Attribution License, which permits unrestricted use, distribution, and reproduction in any medium, provided the original author and source are credited.

\begin{abstract}
The present investigation was performed to clarify the histological features of the left ventricles in the heart of the mature dromedary camel. This investigation was carried out on the left ventricles of six healthy mature camels. Microscopically, the left ventricles is consisted of three major layers or tunics; the internal endocardium, the middle myocardium, and the external epicardium. The endocardium is consisted of three layers; the endothelial layer of simple squamous epithelium, sub-endothelial layer of loose connective tissue and the sub-endocardial layer that connecting the endocardium with the myocardium and housing bundles of the purkinje cardiomyocytes; purkinje fibers. The myocardium, is the middle layer of the ventricular wall, is sandwiched between an outer epicardium, that covers the ventricular wall, and an inner endocardium, that lines the chamber, containing two bundles of cardiac fibers; the working cardiac myocytes (myocardiocytes) and the purkinje bundles. The epicardium is the outer most layer of the ventricular wall. This layer is a relatively thin in comparison with the myocardium and is consisted of a sub-epicardial layer of loose connective tissue which housing many blood vessels, lymph vessels, nerves and adipocytes and mesothelium of simple squamous epithelium.
\end{abstract}

Keywords: Left ventricle; Cardiomyocytes; Purkinje fiber; Camel heart; Purkinje cardiomyocytes

\section{Introduction}

Getty [1], Nickel et al. [2], Reece [3] and Dyce [4] in domestic animals and Smuts and Bezuidenhout [5] in camel and Budras et al. [6] in horse stated that the left ventricle forms the left caudal part of the ventricular mass including the apex of the heart. Its wall is much thicker than the right ventricle. The base of the left ventricle is connected with the left atrium through the left atrioventricular orifice. The latter, is guarded by left atrioventricular valve; bicuspid valve.

A fundamental characteristic of the heart wall is that its thickness varies from location to location where, the outer wall of a ventricle is significantly thicker than the outer wall of an atrium, and the outer wall of the left ventricle is thicker than the outer wall of the right ventricle. The thickness of the heart wall at a specific location is determined by the amount of force it must develop during its contraction [7].

The walls of all four heart chambers are consisted of three major layers or tunics: the internal endocardium; the middle myocardium; and the external epicardium. The latter, is considered the visceral part of serous pericardium; lamina visceralis $[8,9]$.

The three layers that constitute the heart wall are the endocardium, myocardium, and epicardium, homologous to the tunica intima, tunica media, and the tunica adventitia, respectively, of the blood vessels [10]. Moreover, the wall of the heart is much thicker than the wall of the large vessels [11].
The thick wall of the heart is mainly composed of the cardiac muscle cells capable of spontaneous rhythmic contraction, which pumps the blood into the vascular system. The inner layer of the heart is referred to as endocardium and is continuous with the tunica intima of the large blood vessels leaving and entering the heart. The contractile middle muscular layer is called the myocardium and is considered the thickest layer of the heart. The outermost layer is the epicardium [12-14].

The endocardium, is the innermost layer of the heart wall, lining all the heart's cavities including the atria and ventricles, is similar in structure to the tunica intima of adjoining blood vessels $[13,15]$. The endocardium usually consists of three layers; a continuous endothelium (simple squamous epithelium) that composes the inner most layer. Underneath the endothelium are inner and outer subendothelial layers. The inner sub-endothelial layer is composed of dense irregular connective tissue with collagen, elastic fibers. The outer sub-endothelial layer is also referred to as the sub-endocardial layer and is predominantly composed of loosely arranged collagen and elastic fibers. Adipose cells may be present, along with a rich supply of blood and lymph vessels, and in some locations the impulseconducting cardiac muscle fibers (purkinje fibers). The connective tissue is continuous with that of the myocardium [11].

The myocardium, is the middle layer of the heart wall, representing the tunica media of the heart, is considered the thickest layer of the heart wall, making up the bulk of the heart and contains the cardiac muscle throughout most of the heart. This layer is consisting of the cardiac muscle cells that arranged in strands or branching columns whose ends attach to the dense connective tissue which surrounds the valves $[16,11]$. 
Citation: Ghonimi W, Abuel-Atta AA, Bareedy MH, Balah A (2014) Left Ventricles of the Mature Camel Heart (Camelus dromedaries) with Special References to the Structure and Distribution of the Purkinje Cardiomyocytes: Microanatomy. J Cytol Histol 5: 247. doi: $10.4172 / 2157-7099.1000247$

Page 2 of 8

The myocardium is made up of several layers of cardiac muscle cells of differing orientation [17]. Myocardium is composed of bundles and groups of bundles of cardiac muscle cells, the impulse conducting system. Bundle of cardiac muscle cells are embedded in loose connective tissue that contains a dense capillary network, lymph vessels, and autonomic nerve fibers. The amount of interstitial connective tissue is subject to local variations and is greater in the myocardium of the right ventricle than of the left one [12].

The myocardium is the thickest portion of the heart wall, being more developed along the ventricles than the atria. The myocytes are linked to each other in an end to end manner, forming spirally oriented, interwoven chains of cells around each chamber; some of these cells are modified to attach to the fibrous connective tissue element within this layer as well as along the borders of the epicardium and endocardium. Other muscle cells are modified to function in a nerve like manner, providing impulse-conduction, and even others function as endocrine cells [15].

Cardiac muscle cells are also known as myocytes, have the same basic organization as skeletal muscle where, its sarcoplasm is full of parallel contractile myofibrils that shows its characteristic striations of alternating dark and light bands. Involuntary contraction of cardiac muscle is brought about through the sliding filaments. In cardiac muscle, however, contraction is myogenic, meaning that it is a spontaneous, intrinsic rhythmic activity of the muscle cells themselves. Because rhythmic contractile activity is an inherent property of cardiac muscle cells, only the rate of contraction (the heart rate) is regulated by autonomic nerve impulse [16]. Each cell possesses a single, large, oval, centrally placed nucleus; although two nuclei are occasionally present [10].

Ghonimi et al. [18] claimed that in the cross section, the camel left atrial cardiac myocytes appeared as an irregular polygonal cells of various sizes with a large, round, pale-staining, euchromatic, centrally placed, single nucleus and also sometimes, bi-nucleated. The cardiac muscle sarcoplasm is an eosinophilic, full of contractile myofibrils. Moreover, in the longitudinal sections, they appeared long, striated, branched and anastomosed, forming network. Furthermore, most of the cardiac muscle cells possess only a single, relatively large, oval, ovoid pale-staining, more euchromatic and centrally placed nucleus, however, some bi-nucleated cells are occasionally observed. The cardiac muscle sarcoplasm is an eosinophilic, full of parallel contractile myofibrils that are consisted of myofilaments. They exhibit a very stronger cross-striated banding.

Purkinje fibers are a part of the heart conducting system and are large modified cardiac muscle cells. They are terminal branches of the AV bundles, located in sub-endocardial connective tissue. They often appear large in size and cluster as group. Each cell has only one or two centrally placed nuclei and pale staining cytoplasm because of containing large amounts of glycogen. It has fewer myofibrils than regular cardiac muscle cells. They work together with other impulse conducting structures to regulate the heart beats by conveying impulse to neighboring cardiac muscle cells $[11,15]$.

Myocardium of the left ventricle wall is the thickest because of the fact that it must pump the blood out of the ventricles of the heart for a great distance, distribute blood to the tissues and organs of the body and overcome the high pressure and resistance of the systemic circulation [11]. The heart is covered externally by simple squamous epithelium (mesothelium) supported by a thin layer of connective tissue that constitutes the epicardium. A sub-epicardial layer of loose connective tissue contains veins, nerves, and many adipocytes [9].

The aim of our investigation is to through more light on the micro anatomical features of the left ventricles of the mature camel heart and also to clarify the distribution and structure of the purkinje fibers.

\section{Materials and Methods}

Hearts of six apparently healthy mature camels were collected from Zagazig slaughter house in Sharkia province for histological studies. For light microscopy; the left ventricles were immediately fixed in $10 \%$ Neutral Buffered Formalin. The fixed specimens were processed using the usual histological techniques; dehydrated in ascending grades of ethanol series, cleared in benzene and embedded in paraffin. 5-7 $\mu \mathrm{m}$ thick sections were prepared and mounted on glass slides. These are dewaxed in xylene, hydrated in descending grades of ethanol series and stained with Harris's hematoxylin and eosin ( $\mathrm{H}$ and $\mathrm{E})$. The photomicrographs were taken using a digital Dsc-W 130 super steady cyber shot camera connected to an Olympus BX 21 light microscope [19].

\section{Results}

Histologically, the left ventricle is consisted of three major layers; the internal endocardium, the middle myocardium, and the external epicardium. The endocardium is the inner layer of the left ventricular wall and lined the ventricle chambers. It consists of three layers; the endothelial layer, the sub-endothelial layer and the sub-endocardial layer. The endothelium is considered the inner most layer of the endocardium. It is composed of single layer of simple squamous epithelium and sometime simple cuboidal epithelium. The subendothelial layer is the second layer of the endocardium, is a relatively thick and consists of narrow zone of loose connective tissue that is supporting the endothelial layer. Moreover, no clear cut border could be seen separating the endothelium and sub-endothelial layer (Figure 1). Furthermore, the sub-endocardial layer is the deep layer of the endocardium that connects the endocardium with the myocardium. It is composed of loose connective tissue that housing two types of modified cardiomyocytes bundles. The first bundle is including two types of cells; perinuclear clear zone cells ("P" cells) and transitional cells ("T" cells) (Figures 1 and 2). The first one is round or ovoid with perinuclear clear zone so named perinuclear clear zone cells ("P" cells), has few myofibrils in the cytoplasm with single, central, large nucleus with distinct nucleoli and smaller in size than the working cardiomyocytes. The second cell; transitional cells ("T" cells) are observed round or ovoid but smaller in size than the perinuclear clear zone cells without perinuclear clear zone, has more myofibrils than the perinuclear clear zone cells with single, central, large nucleus with distinct nucleoli (Figures 1 and 2).

The second bundle in the sub-endocardial layer is a group of purkinje fibers that observed varying in size. They are round, larger in size than the two types of modified cardiac myocytes and also larger than the ordinary cardiac myocytes. Its cytoplasm is pale as it contains very fewer myofibrils. It has single, central, large nucleus and sometimes binucleated with prominent nucleoli. The nuclear chromatin is dispersed and in most cases tended to be condensed peripherally. Furthermore, some of them were appeared none nucleated (Figures 1 and 3). Moreover, the purkinje cardiomyocytes showed strongly PAS positive reactivity. And also, strongly PAS positive granules are appeared filling the Purkinje cell cytoplasm. The 
Citation: Ghonimi W, Abuel-Atta AA, Bareedy MH, Balah A (2014) Left Ventricles of the Mature Camel Heart (Camelus dromedaries) with Special References to the Structure and Distribution of the Purkinje Cardiomyocytes: Microanatomy. J Cytol Histol 5: 247. doi: $10.4172 / 2157-7099.1000247$

Page 3 of 8

inter-purkinje cardiomyocytes connective tissue is also showed strongly PAS positive reactivity (Figure 4). No clear cut border could be seen separating the sub-endothelial layer and the sub-endocardial layer (Figure 1).

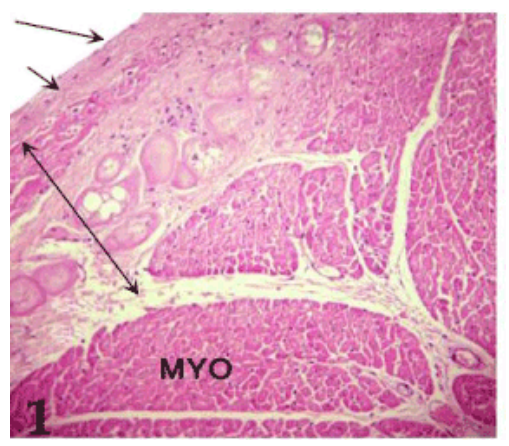

Figure 1: A photomicrograph of the mature camel left ventricle showing the endothelium (long arrow), the sub-endothelium (short arrow), the sub-endocardium (double head arrow), and the myocardium (MYO). Stain: H and E, Obj.x4: Oc.x10.

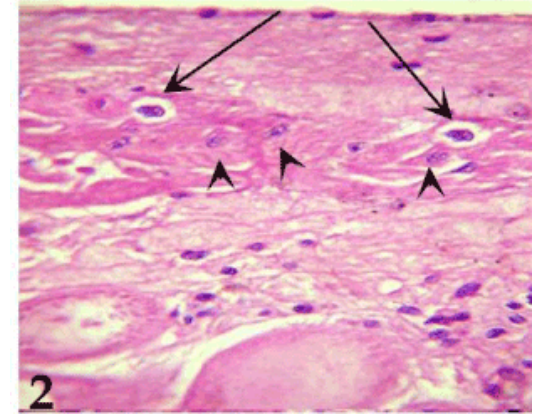

Figure 2: Higher magnification of fig. 1 showing the subendocardial peri-nuclear clear zone cells (long arrow) and the transitional cells (arrow head). Stain: $\mathrm{H}$ and E Obj.x40: Oc.x10.

The myocardium is the middle and thickest layer of the left ventricular wall, making up the bulk or the main mass of the ventricular wall (Figures 5 and 6). The ventricular myocardium is characterized by housing massive, large, numerous cardiac myocytes as a result of the relatively high pressure and overload on the ventricles (Figure 5).

The myocardium consists of cardiac muscle cells that arranged in layers and surrounding the ventricle in a complex spiral. The arrangement of these muscle cells is extremely varied, so that in sections, cells are seen to be oriented in many different directions (Figures 5 and 6). Meanwhile, in other sections, the arrangement of the muscle cell bundles is regular and in one direction especially near the apex (Figures 7 and 8).

The myocardial layer of the left ventricle is including two types of cardiac muscle bundles; bundle of working cardiac myocytes and bundles of purkinje cardiomyocytes (Figures 5, 6, 9-12). The first bundle is a group of working cardiac myocytes that arranged as a sheath in a complex and spiral manner and oriented either in one direction or in different directions. These bundles are surrounded by the epimysium of dense connective tissue, dividing by the perimysium and each muscle fiber is itself surrounded by a more delicate loose connective tissue, the endomysium (Figures 5-7, 10, 13).

These bundles of cardiac muscle cells are laterally separated from each other by a considerable amount of loose connective tissue that is rich with a dense capillary network, lymph vessels, and autonomic nerve fibers (Figures 10-13).

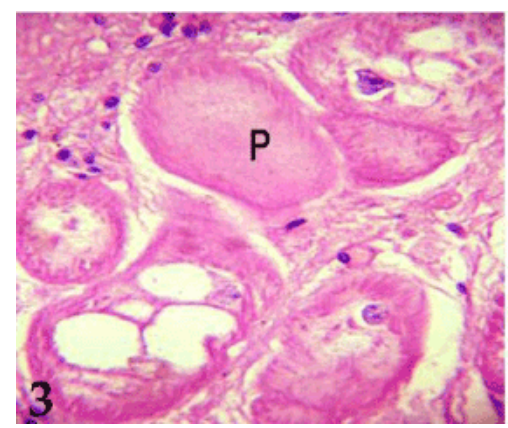

Figure 3: Higher magnification of fig. 1 showing the subendocardial purkinje fiber (P). Stain: $\mathrm{H}$ and E Obj.x40: Oc.x10.

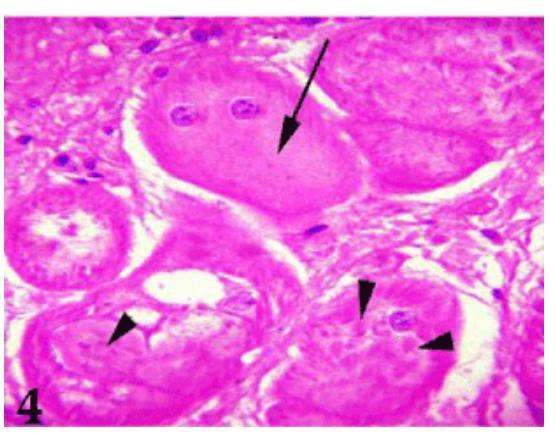

Figure 4: Higher magnification of fig. 1 showing the strongly PAS positive reactivity of the purkinje fiber (arrow) and strongly PAS positive granules (arrow head). Stain: PAS Obj.x40: Oc.x10.

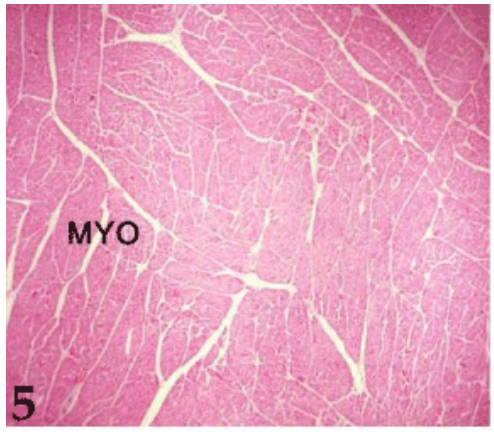

Figure 5: A photomicrograph of the left ventricle myocardium (MYO). Stain: Hand E Obj.x4: Oc.x10. 
Citation: Ghonimi W, Abuel-Atta AA, Bareedy MH, Balah A (2014) Left Ventricles of the Mature Camel Heart (Camelus dromedaries) with Special References to the Structure and Distribution of the Purkinje Cardiomyocytes: Microanatomy. J Cytol Histol 5: 247. doi: $10.4172 / 2157-7099.1000247$

Page 4 of 8

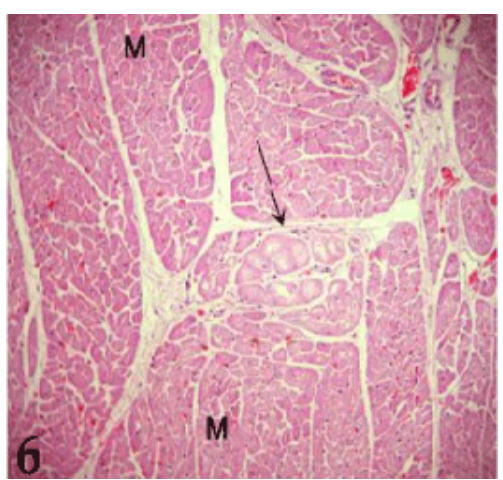

Figure 6: A photomicrograph of the left ventricular myocardium showing the myocardiocytes bundles $(\mathrm{M})$, and the purkinje fibers bundle (arrow). Stain: H and E Obj.x10: Oc.x10.

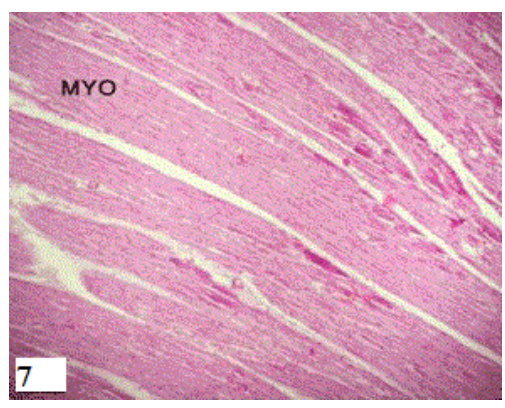

Figure 7: A photomicrograph of the left ventricular myocardium showing the one direction of the myocardiocytes bundles (MYO). Stain: Hand E Obj.x4: Oc.x10.

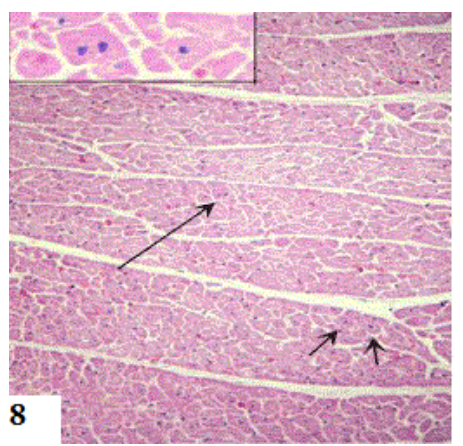

Figure 8: Higher magnification of fig. 11 showing the cardiac myocytes (short arrow) and binucleated cardiac myocytes (long arrow) and higher magnification of cardiac myocytes (black box). Stain: Hand E Obj.x10: Oc.x10.

The intercellular connective tissue is few in the ventricle where the cardiac myocytesare numerous and also much closed to each other, appearing overcrowded (Figures 4 and 5). Most of these cells are elongated, branched and connected with each other, forming some sort of network-like structure (Figures 8, 14-16).
The cardiac muscle cells in longitudinal sections are appeared short, striated, branched and anastomosed, forming network. Furthermore, most of the cardiac muscle cells possess only a single, relatively large, oval, ovoid pale-staining, more euchromatic and centrally placed nucleus, however, some binucleated cells are occasionally observed, occupying a central position in the muscle cell and some of them showed prominent nucleoli. The nuclear chromatin is dispersed and in most cases tended to be condensed peripherally (Figures 15 and 16).

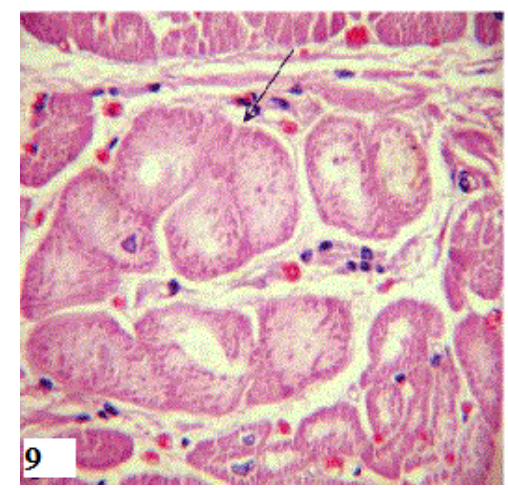

Figure 9: Higher magnification of fig. 5 showing the purkinje fibers bundle (arrow). Stain: Hand E Obj. x 40 : Oc.x10

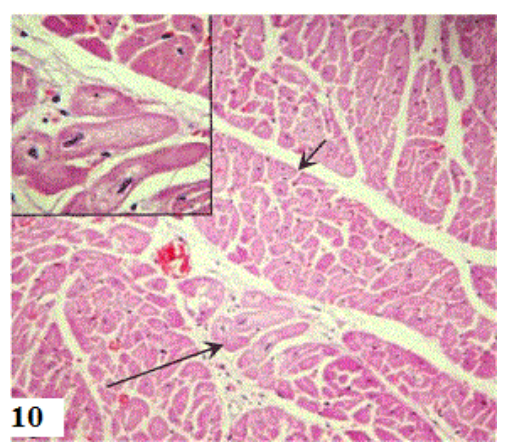

Figure 10: A photomicrograph showing the myocardiocytes bundles (short arrow), the purkinje fibers bundle (long arrow) and higher magnification of purkinje bundles (black box). Stain: Hand E Obj.x10: Oc.x10.

In cross sections, the cardiac muscle fibers appear irregular polygonal cells of various sizes with a large, round, pale-staining, euchromatic, centrally placed, single nucleus and also sometimes, binucleated cells (Figures 8 and 14).

The cardiac muscle sarcoplasmis an eosinophilic, full of parallel contractile myofibrils that are consisted of myofilaments. They exhibit a cross-striated banding pattern where, the sarcoplasm shows its characteristic striations of alternating dark and light bands (Figure 16b). Myocardium of the left ventricle is the thickest in comparisons with the right ventricle and atrial myocardium because of the relatively high pressure, overload and resistance of blood circulation during systole (Figure 5). 
Citation: Ghonimi W, Abuel-Atta AA, Bareedy MH, Balah A (2014) Left Ventricles of the Mature Camel Heart (Camelus dromedaries) with Special References to the Structure and Distribution of the Purkinje Cardiomyocytes: Microanatomy. J Cytol Histol 5: 247. doi: 10.4172/2157-7099.1000247

Page 5 of 8

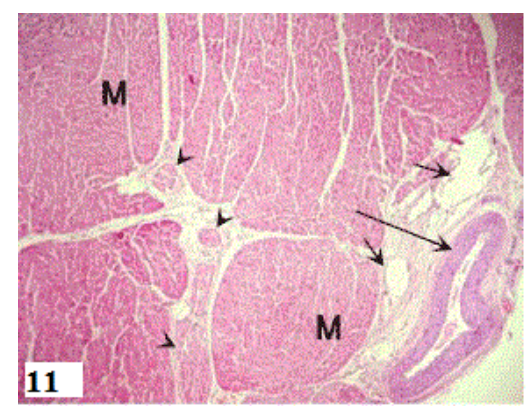

Figure 11: A photomicrograph showing the myocardiocytes bundles $(\mathrm{M})$, the purkinje fibers bundle (arrow head), blood vessels (long arrow) and lymph vessels (short arrow). Stain: Hand E Obj.x4 : Oc.x10.

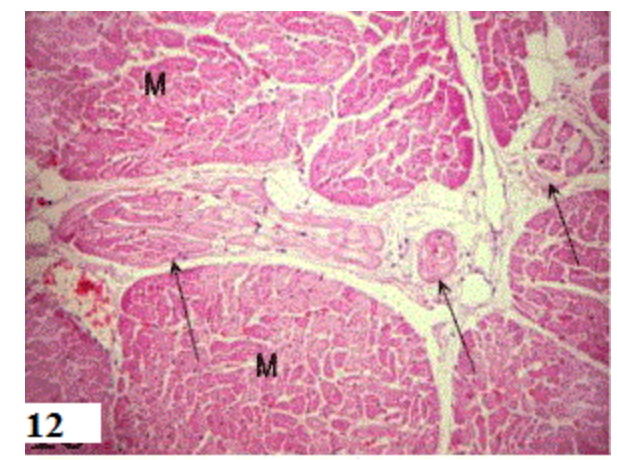

Figure 12: Higher magnification offig. 8 showing the myocardiocytes bundles $(\mathrm{M})$, the purkinje fibers bundles (arrow) Stain: Hand E Obj.x10 : Oc.x10.

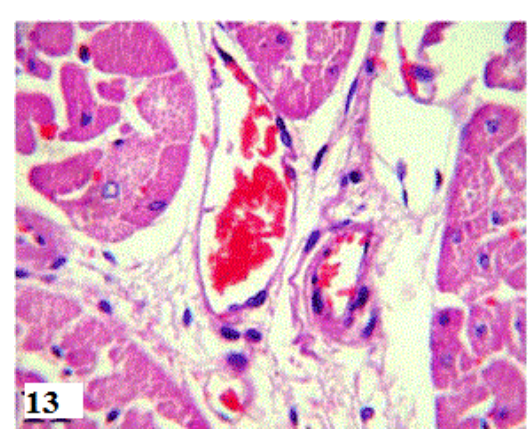

Figure 13: A photomicrograph showing the highly vascularized inter bundle CT. Stain: Hand E Obj.x40 : Oc.x10.

The second bundle of the left ventricular myocardium is a group of purkinje fibers that are observed round, larger in size than the working cardiac myocytes. Its cytoplasm is pale as it contains very fewer myofibrils than normal cardiac myocytes. It has single, central, large nucleus and sometimes binucleated with prominent nucleoli. The nuclear chromatin is dispersed and in most cases tended to be condensed peripherally. However, some non-nucleated cells are also observed (Figure 6, 9-12). Resembling the bundles of the working cardiac myocytes, the purkinje fibers bundles are also surrounded by the epimysium, dividing by the perimysium. Each Purkinje fiber is itself surrounded by a more delicate loose connective tissue, the endomysium (Figures 6, 9-12).

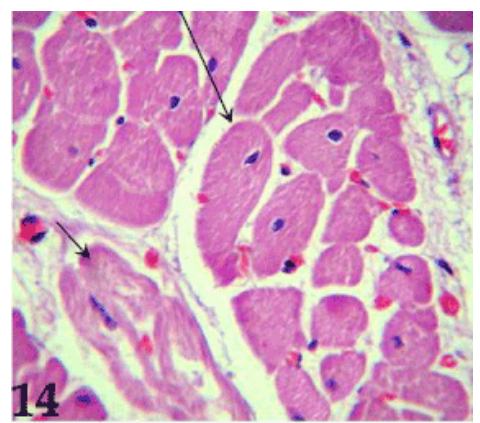

Figure 14: A photomicrograph showing the cross section of the myocardiocytes (long arrow) and the purkinje fibers (short arrow). Stain: Hand E Obj.x40 : Oc.x10.

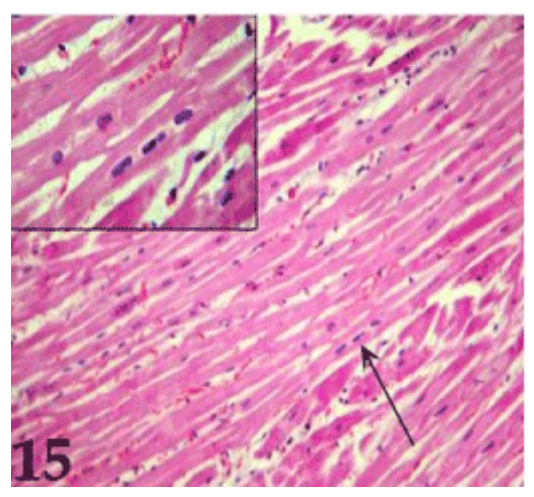

Figure 15: A photomicrograph showing the longitudinal section of the myocardiocytes (arrow) and higher magnification of cardiac myocytes (black box). Stain: Hand E Obj.x10 : Oc.x10.

The epicardium is considered the outer most layer of the ventricular wall. This layer is a relatively thin in comparison with the myocardium. It is consisted of a subepicardial layer and mesothelium. The subepicardial layer is formed from loose connective tissue that housing many blood vessels, lymph vessels, nerves and also massive layer of adipocytes (Figures 17 and 18). The left ventricle is covered externally by a single layer of simple squamous epithelial cells; mesothelium that supported by a subepicardial connective tissue (Figures 17 and 18). Moreover, some bundles of working cardiac myocytes and purkinje cardiomyocytes are observed within the subepicardial connective tissue (Figure 19).

\section{Discussion}

Our result revealed that the left ventricle is consisted of three major layers; the internal endocardium, the middle myocardium, and the external epicardium. Such investigation is very close and similar to the 
Citation: Ghonimi W, Abuel-Atta AA, Bareedy MH, Balah A (2014) Left Ventricles of the Mature Camel Heart (Camelus dromedaries) with Special References to the Structure and Distribution of the Purkinje Cardiomyocytes: Microanatomy. J Cytol Histol 5: 247. doi: $10.4172 / 2157-7099.1000247$

Page 6 of 8

finding that stated by $[9,10,12,16,20]$. Moreover, this result is very close to those described after [21].

The endocardium consists of three layers; the endothelial layer, subendothelial layer and sub-endocardial layer. Such finding is in agreement with [21] who described that the endocardium consists of three sub layers; endothelium, subendothelium and conjunctive tissues pass into perimisial myocardial tissue. Moreover, this investigation is partially agreement with [23] who assumed that the endocardium was formed, from inside, by the endocardium proper, beneath which lay the sub-endocardial layer that intervened between the endocardium proper and the myocardium. The endocardium proper is formed, from inside outwards, of two layers; an inner layer and an outer layer.

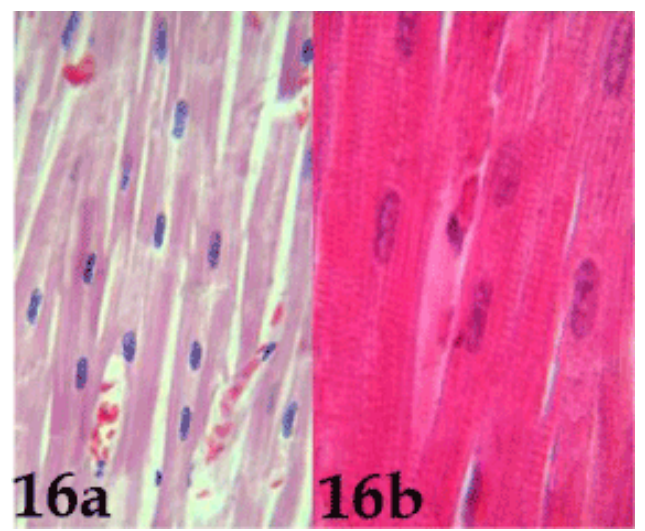

Figure $16 \mathrm{a}, \mathrm{b}$ : A photomicrograph showing $\mathrm{a}, \mathrm{b}$ ) the longitudinal section of the myocardiocytes. Stain: a) Hand E Obj.x40: Oc.x10 b) HandE Obj.x100: Oc.x10.

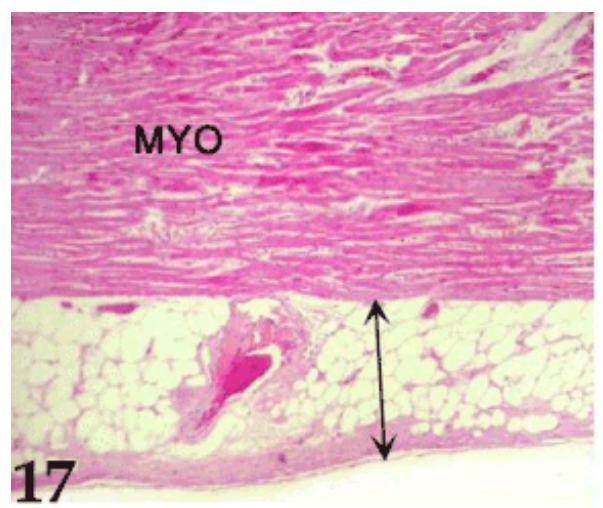

Figure 17: A photomicrograph showing the myocardium (MYO), and the epicardium (double head arrow). Stain: Hand E Obj.x4: Oc.x10.

The endothelium is considered the inner most layer of the endocardium. It is composed of single layer of simple squamous epithelium and sometime simple cuboidal epithelium. This result is in agreement with $[9,10,15,16,20$,]. Furthermore, such investigation is in partially agreement with [23] who clarified that the endothelial layer is the inner layer of the endocardium and is formed of polygonal endothelial cells.
The sub-endothelial layer is the second layer of the endocardium, consists of narrow zone of loose connective tissue that supporting the endothelial layer. Such result is very close and similar to the finding that described after [23] who confirmed that the sub-endothelial layer, is the outer layer of the endocardium and is formed of connective tissue cells and fibers that are mainly of elastic and collagen fibers. Moreover, our investigation revealed that there is no clear cut border could be seen separating the endothelium and sub-endothelial layer. This result is very close to those described after [21].

Our result clarified that the sub-endocardial layer is the deep layer of the endocardium which is composed of loose connective tissue that includes two types of modified cardiac muscle cells; the perinuclear clear zone cell (P. cells) and the transitional cells (T. cells). Such result is very close and similar to the finding that described after [23].

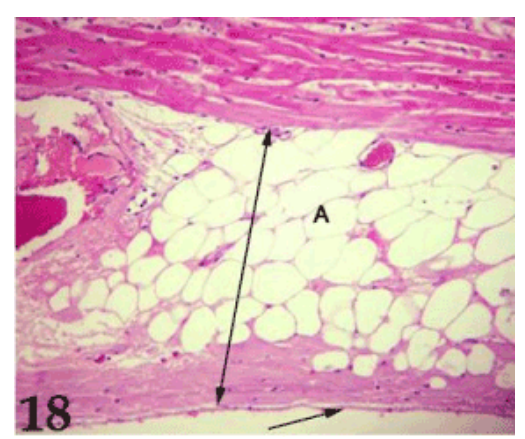

Figure 18: Higher magnification of figure. 17 showing the epicardium (double head arrow). Stain: Hand E Obj.x10: Oc.x10.

The endocardiumis the inner layer of the ventricular wall and lined the ventricular chambers. Such investigation is very close and similar to the finding that stated by $[8,10-13,15,16,22]$.

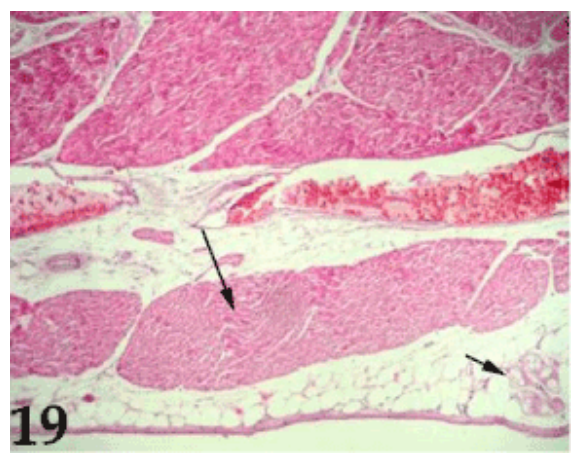

Figure 19: A photomicrograph of the epicardium showing the cardiac muscle bundle (long arrow), and the purkinje bundle (short arrow).Stain: Hand E Obj.x4 : Oc.x10.

Our investigation claimed that the presence of branch of impulse conducting system; purkinje fibers within the sub-endocardial layer. Such result is very close and similar to the finding of $[8-10,12,13,15,16,20,22]$.

No clear cut border could be seen separating the endocardium and the sub-endocardial layer. Such result is very close and similar to the finding that described after [23]. 
Citation: Ghonimi W, Abuel-Atta AA, Bareedy MH, Balah A (2014) Left Ventricles of the Mature Camel Heart (Camelus dromedaries) with Special References to the Structure and Distribution of the Purkinje Cardiomyocytes: Microanatomy. J Cytol Histol 5: 247. doi: $10.4172 / 2157-7099.1000247$

Page 7 of 8

The present investigation revealed that the myocardium is the middle and thickest layer, making up the bulk or the main mass of the left ventricular wall. It is sandwiched between the epicardium and the endocardium. Such investigation is very close and similar to the finding that stated by $[9,10,12,15,16]$. Moreover, this result is very close and similar to the finding that described after [23] who demonstrated that the myocardium is the thickest coat of the atrial wall that lay between the endocardium and the epicardium.

Myocardium of the left ventricle is the thickest in comparisons with the right ventricle and atrial myocardium because of the relatively high pressure and resistance of blood circulation. This investigation is completely goes hand in hand with [7] who stated that a fundamental characteristic of the heart wall is that its thickness varies from location to location where, the outer wall of a ventricle is significantly thicker than the outer wall of an atrium, and the outer wall of the left ventricle is thicker than the outer wall of the right ventricle. The thickness of the heart wall at a specific location is determined by the amount of force it must develop during its contraction. And also goes hand in hand with [11] who stated that the atria have thinner walls than the ventricles where the difference in thickness of the atrial and ventricular walls correlates with differences in pressure and workloads.

The myocardium consists of cardiac muscle cells arranged in layers that surround the left ventricle in a complex spiral. The arrangement of these muscle cells is extremely varied, so that in sections, cells are seen to be oriented in many directions and in some section are in one direction. This investigation is completely goes hand in hand with [17] who stated that the myocardium is made up of several layers of cardiac muscle cells of differing orientation. Moreover, this result is in agreement with $[9,10]$.

The myocardium is made up of several layers of cardiac muscle cells of differing orientation that forming groups of cardiac muscle bundles. These bundles are surrounded by the epimysium, an external sheath of dense connective tissue surrounding the entire muscle. From the epimysium, thin septa of connective tissue extend inward, surrounding the fascicles or bundles of fibers within a muscle. The connective tissue around each fascicle is called the perimysium. Each muscle fiber is itself surrounded by a more delicate loose connective tissue, the endomysium. This investigation is goes hand in hand with [24] who reported that delicate connective tissue (endomysium) surrounded the individual muscle fibers and contained small capillaries. Larger amounts of connective tissue (perimysium) surrounded bundles of fibers, and contained larger blood vessels. And also, this investigation is completely goes hand in hand with [9] and also with [25] who stated that the loose connective tissue is arranged around and between muscle fibers and bundles to transmit the pull of the muscle to its attachment. It carries blood vessels, lymphatics and nerves to muscle cells. The epimysium, is the outer coat of the muscle, formed of dense collagenous connective tissue. The Perimysium is the connective tissue trabeculae which divided the muscle fibers into bundles or fascicles. Endomysium is a delicate highly vascularized loose connective tissue profusely supplied by capillaries and lymphatics where the endomysium appearing as slit-like regions between the muscle fibers. The cardiac muscle fibers are attached to the endomysium by their surrounding basement membrane.

Beside the cardiac muscle bundles, the purkinje fiber bundles are also present within the left ventricular myocardium. This finding is in parallelism with [26].
Our investigation revealed that most of the cardiac muscle cells possess only a single, relatively large, oval, ovoid pale-staining, more euchromatic and centrally placed nucleus, however, some binucleated cells are occasionally observed, occupying a central position in the muscle cell and some of them showed prominent nucleoli. The nuclear chromatin is dispersed and in most cases tended to be condensed peripherally. Such investigation is very close and similar to the finding that described by $[23,24,26,27]$ who claimed that some myocardiocytes possessed single, oval and euchromatic nuclei while others possessed double nuclei. The nuclei were centrally located and some of them showed prominent nucleoli. Furthermore, our result revealed that in cross sections, the cardiac muscle fibers appear irregular polygonal cells of various sizes with a large, round, pale-staining, euchromatic, centrally placed, single nucleus and also sometimes, binucleated cells. These results are in coincidence with $[13,15,18,20]$.

The intercellular connective tissue is few in the ventricle where the cardiac myocytes are numerous and also much closed to each other, appearing overcrowded. Most of these cells are elongated, branched and connected with each other, forming some sort of network-like structure. These results are in parallelism with [26].

The cardiac muscle sarcoplasmis an eosinophilic, full of parallel contractile myofibrils that are consisted of myofilaments. They exhibit a cross-striated banding pattern. The sarcoplasm shows its characteristic striations of alternating dark and light bands. Such investigation is in parallelism with $[8,10,11,13-16,18,20,23,24,26,27]$.

The epicardium is considered the outer most layer of the heart. This layer is a relatively thin in comparison with the myocardium and is consisted of a subepicardial layer of loose connective tissue that housing many blood vessels, lymph vessels, nerves and a wide layer of adipocytes. The heart is covered externally by a single layer of a thin and flattened cells that are typical of simple squamous epithelial cells; mesothelium that supported by a subepicardial connective tissue. Such investigation is in parallelism with $[10,16,20,24]$.

\section{Conclusion}

Our investigation was concluded that the purkinje cardiomyocytes bundles were distributed in two areas within the left ventricular wall. The first area is in the sub-endocardiallayer that connecting the endocardium with the myocardium. Furthermore, the second distribution is in the myocardium surrounding the working cardiac myocytes bundles. Purkinje fibers are large modified cardiac muscle cells. They often appear larger in size than the working cardiac myocytes and cluster as group. Each cell has only one or two nuclei. It has fewer myofibrils than the cardiac muscle cells that arranged peripherally leaving perinuclear clear zone. The perinuclear clear zone giving a pale staining and vacuolated cytoplasm for the purkinje fibers. Moreover, the wall of the left ventricle is relatively thick in comparison with the atrial wall as the over load of the mechanical forces and high pressure on the ventricle during systole.

\section{References}

1. Getty R (1975) The anatomy of the domestic animals. (5thedn) W.B. Saunders Company, Philadelphia, London, Toronto, Canada.

2. Nickel R, Schummer A, Seiferle E (1981) The anatomy of the domestic animals, (2ndedn), Verlag Paul Parey Berlin. Hamburg.

3. Reece WO (2009) Text book of functional anatomy and physiology of domestic animals. (4thedn) Wiley-Blackwell. 
Citation: Ghonimi W, Abuel-Atta AA, Bareedy MH, Balah A (2014) Left Ventricles of the Mature Camel Heart (Camelus dromedaries) with Special References to the Structure and Distribution of the Purkinje Cardiomyocytes: Microanatomy. J Cytol Histol 5: 247. doi: 10.4172/2157-7099.1000247

Page 8 of 8

4. Dyce KM, Wensing CJG, Sack WO (2010) Textbook of Veterinary anatomy. (4thedn) Saunders.

5. Smuts MMS, Bezuidenhout AJ (1987) Anatomy of the dromedary. Clarendon Press, Oxford.

6. BudrasK, Habel RE (2003) Bovine anatomy. (1stedn) Schlutersche, Hannover, Germany.

7. Bergman RA, Afifi AK, Heidger PM (2005) Atlas of Microscopic Anatomy: A Functional Approach: Companion to Histology and Neuroanatomy: Second Edition. The University of Iowa.

8. Junqueira LC, Carneiro J, Kelly I (2007) Basic Histology. (11thedn) McGraw- Hill Co., Medical Publishing Division, New York, Chicago, USA.

9. Mescher AL (2010) Junqueira's Basic Histology: text and atlas. (12thedn), McGraw- Hill Co., Medical Publishing Division, United States of America.

10. Gartner LP, Hiatt JL (2007) Color Text Book of Histology, 3rd Edition. Baltimore, Maryland, 251- 269.

11. Cui D, Naftel JP, Lynch JC, Yang G, Daley WP, et al. (2011) Atlas of Histology with functional and clinical correlations. (1stedn) Baltimore, New york, USA.

12. Dellmann HD, Eurell J (1998) Text book of veterinary histology. (5thedn) Williamsand Wilkins, Baltimore, Maryland, USA.

13. Eurell JAC (2004) Veterinary Histology. Teton Newmedia, United States of America.

14. Hodge P (2013) Color atlas of veterinary histology. (3rdedn), WileyBlackwell, West Sussex, Australia.

15. Samuelson DA (2007) Textbook of Veterinary Histology. Gainesville, Florida.

16. Cormack DH (2001) Essential histology. (2ndedn) Baltimore, Maryland, U.S.A.
17. Fawcett DW, Jensh RP (1997) Concise histology. London. and New York, 126-127.

18. Ghonimi W, Abuel-atta AA, Bareedy MH, Balah A (2014) Left Atrium of the Mature Dromedary Camel Heart (Camelus dromedaries): Microanatomy. Journal of Advanced Veterinary Research 4: 67-76.

19. Bancroft JD, Gamble M (2001) Theory and practice of histological techniques. (5thedn) Churchill livingstone.

20. Eurell J, Frappier BL (2006) Dellmanna ${ }^{\mathrm{Tw}} \mathrm{s}$ Textbook of Veterinary Histology. (6thedn) Blackwell, New York and London, USA.

21. Vladova D, Dimitrov D, Kostov D, Savov S, Stefanov M (2009) Structural and histochemical studies on heart ventricle wall in the cat. Trakia Journal of Sciences, 7: 54-47.

22. Banks WJ (1992) Applied Veterinary Histology. (3rdedn) Philadelphia.

23. Youssef AR, Samir M, Omar E (1988) Study of the anatomy and histology of the atria in the albino $\operatorname{rata}^{\text {Tw }}$ s heart. M. B., B. Ch. Thesis (Histology) Fac. Med. Ain shams university.

24. Abeer E El-Mehy, Mansour FK, Nariman A. Abd El-Fattah, Fatma A. ElSaftt, El-Fiky MM (2008) Histological and immunohistochemical study on the effect of doxorubicin on the heart of adult albino rat and the possible protective role of an antioxidant. Menoufiya Medical Journal, 21: 91-108.

25. Ghallab A (2000) Introduction to functional and clinical histology. (4thedn) Giza, Egypt.

26. Marei HE, Osman AK, Caceci T (1994) A histological approach on the myoendocrine cells of the camel heart. Ph. D. Thesis. Fac. Vet. Med. Suez Canal University.

27. Osman AH, Sato S, Caceci T, Pfeiffer DC (2010) Apoptosis in the myocardium of the adult dromedary camel: ultrastructural characterization. AnatHistolEmbryol 39: 34-41. 